\title{
Evidence for the Involvement of B Lymphoid Cells in Polycythemia Vera and Essential Thrombocythemia
}

\author{
Wendy H. Raskind, Robert Jacobson, Scott Murphy, John W. Adamson, and Philip J. Fialkow \\ Department of Medicine, Divisions of Ambulatory Medicine, Hematology, and Medical Genetics, University of Washington, Seattle, \\ Washington 98195; Division of Hematology, Department of Medicine, Georgetown University School of Medicine, \\ Washington, DC 20007; Cardeza Foundation for Hematologic Research and Department of Medicine, \\ Jefferson Medical College, Philadelphia, Pennsylvania 19107
}

\begin{abstract}
Previous studies with the X-chromosome-linked glucose-6phosphate dehydrogenase (G6PD) as a marker of cellular mosaicism demonstrated that polycythemia vera (PV) and essential thrombocythemia (ET) are clonal disorders of hematopoietic stem cells that can differentiate to erythrocytes, granulocytes, and platelets. To determine if the involved stem cells could also differentiate along the B-lymphoid pathway, we studied one woman with PV and one woman with ET. Of 117 Epstein-Barr virus-transformed B-lymphoblastoid lines expressing a single G6PD derived from the patient with PV, 108 expressed G6PD type $A$, the type characteristic of the abnormal clone. The ratio of 108:9 was significantly different from the one to one ratio predicted for this patient, which suggested that at least some circulating progenitors for Blymphoid cell lines differentiate from the stem cell involved by the disease. Results obtained from the patient with ET were similar-104 of the 109 lymphoblastoid lines monotypic for G6PD expression displayed the enzyme type found in the abnormal clone of marrow cells. Therefore, in these patients, PV and ET, like chronic myelogenous leukemia, involve a stem cell pluripotent for the lymphoid as well as the myeloid series.
\end{abstract}

\section{Introduction}

The myeloproliferative diseases are a diverse group of disorders characterized by abnormal proliferation of a subset of marrow elements. In polycythemia vera (PV) ${ }^{1}$ there are elevated white cell and platelet counts and increased red cell mass, whereas in essential thrombocythemia (ET) increases in megakaryocytes and platelets are the predominant findings. Previous studies have shown that PV and ET are clonal diseases that arise in stem cells that are multipotent for erythrocytes, granulocytes,

Address reprint requests to Dr. Raskind, Department of Medicine, RG25, University of Washington School of Medicine.

$$
\text { Received for publication } 11 \text { January } 1985 .
$$

1. Abbreviations used in this paper: cIg, cytoplasmic Ig; CLL, chronic lymphocytic leukemia; CML, chronic myelogenous leukemia; EBV, Epstein-Barr virus; ET, essential thrombocythemia; G6PD, glucose-6phosphate dehydrogenase.

J. Clin. Invest.

(C) The American Society for Clinical Investigation, Inc.

$0021-9738 / 85 / 04 / 1388 / 03 \$ 1.00$

Volume 75, April 1985, 1388-1390 and platelets (1-3). Recent work has documented the involvement of B lymphocytes in another myeloproliferative disorder, chronic myelogenous leukemia (CML) (4-6). We report here evidence that the pluripotent stem cells involved by $\mathrm{PV}$ and ET also can differentiate to B-lymphoid cells.

As in our previous work, we used the X-chromosomelinked glucose-6-phosphate dehydrogenase (G6PD) as a marker to trace hemopoietic cell lineages. One of the two G6PD genes in XX somatic cells is randomly inactivated early in embryogenesis; therefore, women heterozygous at the G6PD locus for the usual gene $\left(G d^{\mathrm{B}}\right)$ and a variant allele such as $G d^{\mathrm{A}}$ have cellular mosaicism, with some of their cells expressing B-type G6PD and others manifesting A-type enzyme. Normal tissues in a $G d^{\mathrm{B}} / G d^{\mathrm{A}}$ heterozygote display both enzyme types, whereas clonal proliferations manifest only a single enzyme.

\section{Methods}

Patient 1. The diagnosis of PV was made in 1968 when the patient was 49-yr-old (case 1 in reference 1). On July 13, 1983, when blood was first obtained for establishing B-lymphoid cell lines, the white cell count was $55,600 / \mathrm{mm}^{3}$, with $78 \%$ polymorphonuclear cells, $5 \%$ band forms, 3\% metamyelocytes, $6 \%$ lymphocytes, $5 \%$ monocytes, and $2 \%$ eosinophils. The hematocrit was $37.5 \%$, hemoglobin $10.1 \mathrm{~g} / \mathrm{dl}$, mean cell volume $80.0 \mu \mathrm{m}^{3}$, mean cell hemoglobin $21.3 \mathrm{pg}$, and mean cell hemoglobin concentration $27 \%$. The platelet count was $613,000 / \mathrm{mm}^{3}$. Treatment has been limited to phlebotomy.

Patient 2. ET was diagnosed in 1976 when the patient was $31-\mathrm{yr}$ old (patient 2 in reference 2). The patient received short courses of busulphan in January 1979, March 1981, and May 1983. On May 30, 1984, when B-lymphoid cell studies were done, the hematocrit was $41 \%$, platelet count $876,000 / \mathrm{mm}^{3}$, and white cell count $4,900 / \mathrm{mm}^{3}$, with $49 \%$ polymorphonuclear cells, $5 \%$ bands, $33 \%$ lymphocytes, $5 \%$ monocytes, $3 \%$ eosinophils, $2 \%$ basophils, and $3 \%$ atypical lymphocytes.

Specimens. After informed consent was obtained, peripheral blood was drawn into sterile tubes that contained either EDTA or preservativefree heparin. Samples were air transported from Philadelphia or Washington, DC and received in Seattle within $24 \mathrm{~h}$ after being obtained.

Epstein-Barr virus (EBV) transformation. Peripheral blood from patient 1 was sedimented at unit gravity in $3 \%$ dextran in phosphatebuffered saline, $\mathrm{pH} 7.2$, for $30 \mathrm{~min}$ at room temperature to remove excess erythrocytes and to facilitate separation of mononuclear cells (7). Mononuclear cells were obtained from all specimens by sedimentation of the blood over Isolymph (Gallard-Schlesinger, Carle Place, NY) (7) and depletion of E-rosetting cells with neuraminidase-treated sheep erythrocytes (8). The B-lymphocyte-enriched nonrosetting mononuclear cells were mixed with an equal volume of EBV-containing medium and plated at densities varying between 10,000 and 70,000 cells/well in 96-well microculture trays (Corning Glass Works, Corning, NY) and maintained with twice weekly feedings as described (7). 
G6PD analyses. Aliquots of erythrocytes, platelets, granulocytes, and B-lymphoid cells were prepared and starch-gel and celluloseacetate electrophoreses were performed as described $(9,10)$. The ratio of A/B enzyme was estimated visually. The sensitivity of this technique allows the detection of a minor enzyme component as small as $5 \%$.

Cytoplasmic Ig (cIg) determination. Indirect immunofluorescence was performed on cytocentrifuge slides with purified mouse monoclonal anti-human Ig, $\lambda$ and $\kappa$ light chains (Becton-Dickinson Monoclonal Center, Inc., Mountain View, CA) and fluorescein isothiocyanatelabeled goat anti-mouse IgG (Cappel Laboratories Inc., Cochranville, PA).

\section{Results}

G6PD analyses-patient 1. Analysis of skin and cultured skin fibroblasts in 1975 revealed the patient to be heterozygous for G6PD with a 1:1 ratio of $A / B$ enzyme. When first studied in 1975 and again in 1983 at the time of initiation of Blymphoblastoid cell lines, only type A G6PD was found in granulocytes, platelets, and erythrocytes, which indicated that the disease was clonal and involved a multipotent stem cell.

Patient 2. The ratio of A/B G6PD activity was found to be $1: 1$ in skin and cultured skin fibroblasts in 1980. More than 95\% type B G6PD was expressed in granulocytes, erythrocytes, and platelets initially and in 1984 when EBV transformation was performed. (Less than 5\% type A G6PD was detected in the white cell fractions, an amount that is below the expected limit of sensitivity of the gel methods used.)

B-lymphoblastoid cell lines. In contrast to the difficulty in obtaining EBV-transformed lines from patients with CML (5), chronic lymphocytic leukemia (CLL) (11-14), or myelodysplastic anemia (7), 191 and 144 lines were recovered from 480 and 340 wells plated for patients 1 and 2, respectively (Table I). These high transformation efficiencies were accompanied by increases in the proportions of lines that were derived from more than one progenitor cell, as evidenced by the high frequency of lines displaying both enzyme types ( 39 and $24 \%$, patients 1 and 2, respectively). Of the 117 lines expressing a single G6PD derived from the patient with PV (patient 1), 108 displayed type A enzyme and 9 expressed type B, whereas 104 of the 109 lines that were monotypic for G6PD expression established from the patient with ET displayed type B enzyme. The frequencies of tested lines producing a single light chain type were $43 \%$ for patient 1 and $66 \%$ for patient 2 . There was no correspondence between the Ig light chain type and the

Table I. G6PD Types Expressed by

B-Lymphoblastoid Cell Lines*

\begin{tabular}{ccrrr}
\hline $\begin{array}{l}\text { Date blood } \\
\text { sample obtained }\end{array}$ & $\begin{array}{c}\text { Number of } \\
\text { lines tested }\end{array}$ & B & A & B/A \\
\hline Patient 1 (PV) & & & & \\
$7 / 14 / 83$ & 71 & 8 & 52 & 11 \\
$10 / 25 / 83$ & 120 & 1 & 56 & 63 \\
Totals & 191 & 9 & 108 & 74 \\
Patient 2 (ET) & & & & \\
$5 / 30 / 84$ & 35 & 18 & 0 & 17 \\
$6 / 14 / 84$ & 109 & 86 & 5 & 18 \\
Totals & 144 & 104 & 5 & 35 \\
& & & &
\end{tabular}

* The abnormal hemopoietic clone in patient 1 expressed G6PD type $\mathrm{A}$, and in patient 2 the abnormal clone expressed G6PD type B.
Table II. cIg Light Chain Expression in

Lines Producing Only a Single G6PD

\begin{tabular}{|c|c|c|c|c|c|c|c|c|}
\hline \multirow{2}{*}{$\begin{array}{l}\text { Date sample } \\
\text { obtained }\end{array}$} & \multicolumn{4}{|c|}{ Lines producing G6PD A } & \multicolumn{4}{|c|}{ Lines producing G6PD B } \\
\hline & $\kappa$ & $\lambda$ & Mixed & $\mathrm{NT}^{*}$ & $\kappa$ & $\lambda$ & Mixed & $\mathrm{NT}^{*}$ \\
\hline \multicolumn{9}{|c|}{ Patient 1 (PV) } \\
\hline $7 / 14 / 83$ & 14 & 8 & 28 & 2 & 1 & 2 & 4 & 1 \\
\hline $10 / 25 / 83$ & 12 & 6 & 27 & 11 & 1 & & & \\
\hline Total & 26 & 14 & 55 & 13 & 2 & 2 & 4 & 1 \\
\hline \multicolumn{9}{|c|}{ Patient 2 (ET) } \\
\hline $5 / 30 / 83$ & & & & & 6 & 2 & 9 & 1 \\
\hline $6 / 14 / 84$ & 1 & 0 & 3 & 1 & 25 & 15 & 13 & 33 \\
\hline Total & 1 & 0 & 3 & 1 & 31 & 17 & 22 & 34 \\
\hline
\end{tabular}

* NT, not tested.

G6PD enzyme that was produced in lines monotypic for both characteristics (Table II).

\section{Discussion}

PV and ET are members of a group of myeloproliferative disorders that are characterized by clonal proliferation of multipotent stem cells $(1-3,15,16)$. Employing the technique of EBV transformation to establish multiple B-lymphoblastoid cell lines from a single individual with $\mathrm{CML}$, Martin and coworkers (5) demonstrated that the multipotent stem cell involved by the disease also could differentiate along the B-lymphocyte pathway. Bernheim et al. (17) reached a similar conclusion using a different technique.

Although G6PD typing could be performed directly on separated peripheral blood fractions, reliable information on lymphocytes could not be obtained, since contamination of the mononuclear cell preparations by red cells, granulocytes, and platelets could not be prevented. An attempt to obtain a pure population of $B$ lymphocytes from peripheral blood from patient 1 by using a monoclonal antibody against B cells (B1, a gift from Dr. Paul Martin, Divisions of Oncology, University of Washington and Fred Hutchinson Cancer Research Center, Seattle, WA) and sorting on a fluorescence-activated cell sorter (Ortho System 50HH Cytofluorograf with model 2150 computer, Ortho Diagnostic Systems, Westwood, MA) was unsuccessful, since the desired cells comprised $<1 \%$ of the total. Therefore, we established multiple EBV-transformed B-lymphoblastoid lines from samples of peripheral blood from each of these patients.

In both patients, the ratios of lines producing only type A G6PD to those producing only type $B$ were significantly different from the 1:1 ratios predicted for normal tissues in these patients $(18)(P<0.001$, two-tailed binomial test of proportions [19]). The notable excesses of lines producing the G6PD types characteristic of the neoplastic clones strongly suggest that at least some circulating progenitors for B-lymphoblastoid cell lines derive from the stem cells involved by PV and ET.

Between 24 and $40 \%$ of the B-lymphoid cell lines established from the patients were composed of admixtures of G6PD type A- and B-producing cells. This situation could occur if multiple cells per well initially became transformed by EBV (compatible with the high transformation efficiencies observed -38 and 
$42 \%$, respectively), especially if nonclonally derived B lymphocytes enjoy a selective advantage in vitro (as has been postulated for CML [5] and CLL [14]).

Although the nonclonal G6PD type was not detected in granulocyte, erythrocyte, or platelet fractions from either patient, both enzyme types were seen in cultured B-lymphoid cells. It is likely that some of these nonclonally derived cells antedated the development of the diseases, since many lymphocytes are long-lived. In addition, lymphocytes are capable of proliferation outside the marrow. Furthermore, testing cultured cells may overestimate the in vivo proportion of nonclonal cells, since these normal cells may enjoy a selective advantage in vitro.

The lines were tested for the presence of cIg to confirm their B-lymphocyte derivation and to examine the differentiative potential of the stem cells involved by the two diseases. Ig light chain expression in the lines producing the G6PD type characteristic of the abnormal clone was not uniform for either of the patients studied. More than a third of the lines exhibited a mixture of light chain types (Table II). Presumably these mixed lines arose from more than one cell, but among those lines expressing the G6PD enzyme characteristic of the abnormal clone that were monotypic for Ig light chain, the ratios of $\kappa$ to $\lambda$ producers was $26: 14$ and $31: 17$, not significantly different from the relative proportions of $\kappa: \lambda$ generally found in vivo. This finding suggests that, as in the case of CML (5), light chain Ig gene rearrangement was not yet fixed in the PV and ET stem cells that gave rise to B-lymphoid cells.

In summary, PV and ET, like CML, involve pluripotent stem cells capable of differentiation to Ig-producing B-lymphoid cells as well as to myeloid cells.

\section{Acknowledgments}

We thank Gabriel Herner, Mark Matsushita, Mary Schwar, Laura Steinmann, and Cheryl Tabachnick for their assistance. Operation of the fluorescence-activated cell sorter is supervised by Dr. Peter Rabinovitch, whose help we gratefully acknowledge.

This work was supported by grants CA16448 and AM19410 from the National Institutes of Health.

\section{References}

1. Adamson, J. W., P. J. Fialkow, S. Murphy, J. F. Prchal, and L. Steinmann. 1976. Polycythemia vera: stem-cell and probable clonal origin of the disease. New Engl. J. Med. 295:913-916.

2. Fialkow, P. J., G. B. Faguet, R. J. Jacobson, K. Vaidya, and S. Murphy. 1981. Evidence that essential thrombocythemia is a clonal disorder with origin in a multipotent stem cell. Blood. 54:916-919.

3. Gaetani, G. F., A. M. Ferraris, S. Galiano, P. Giuntini, L. Canepa, and M. d'Urso. 1982. Primary thrombocythemia: clonal origin of platelets, erythrocytes, and granulocytes in a $\mathrm{Gd}^{\mathrm{B}} / \mathrm{Gd}^{\text {Mediterranean }}$ subject. Blood. 59:76-79.

4. Fialkow, P. J., A. M. Denman, and R. J. Jacobson. 1978. Origin of some lymphocytes from leukemic stem cells. J. Clin. Invest. 62: 815-823.

5. Martin, P. J., V. Najfeld, J. A. Hansen, G. K. Penfold, R. J. Jacobson, and P. J. Fialkow. 1980. Involvement of the B-lymphoid system in chronic myelogenous leukemia. Nature (Lond.). 287:49-50.

6. Fialkow, P. J., P. J. Martin, V. Najfeld, G. K. Penfold, R. J. Jacobson, and J. A. Hansen. 1981. Evidence for a multistep pathogenesis of chronic myelogenous leukemia. Blood. 58:158-163.

7. Raskind, W. H., N. Tirumali, R. Jacobson, J. Singer, and P. J. Fialkow. 1984. Evidence for a multistep pathogenesis of a myelodysplastic syndrome. Blood. 63:1318-1323.

8. Bentwich, Z., S. D. Douglas, E. Skutelsky, and H. G. Kunkel. 1973. Sheep red cell binding to human lymphocytes treated with neuraminidase: enhancement of $\mathrm{T}$ cell binding and identification of a subpopulation of B cells. J. Exp. Med. 137:1532-1537.

9. Fialkow, P. J., S. M. Gartler, and A. Yoshida. 1967. Clonal origin of chronic myelocytic leukemia in man. Proc. Natl. Acad. Sci. USA. 58:1468-1471.

10. Sparkes, R. S., M. C. Baluda, and D. E. Townsend. 1969. Cellulose acetate electrophoresis of human glucose-6-phosphate dehydrogenase. J. Lab. Clin. Med. 75:531-534.

11. Levitt, M. L., W. E. Barry, M. K. Helfrich, B. K.-M. Hecht, and F. E. Henderson. 1983. Characterization of Epstein-Barr viruscarrying lines established from chronic lymphocytic leukemia. Cancer Res. 43:1195-1203.

12. Rickinson, A. B., S. Finerty, and M. A. Epstein. 1982. Interaction of Epstein-Barr virus with leukaemic B cells in vitro. I. Abortive infection and rare cell line establishment from chronic lymphocytic leukaemic cells. Clin. Exp. Immunol. 50:347-354.

13. Karande, A., P. J. Fialkow, K. Nilsson, S. Povey, G. Klein, V. Najfeld, and G. Penfold. 1980. Establishment of a lymphoid cell line from leukemic cells of a patient with chronic lymphocytic leukemia. Int. J. Cancer. 26:551-556.

14. Najfeld, V., P. J. Fialkow, A. Karande, K. Nilsson, G. Klein, and G. Penfold. 1980. Chromosome analyses of lymphoid cell lines derived from patients with chronic lymphocytic leukemia. Int. J. Cancer. 26:543-549.

15. Fialkow, P. J. 1980. Clonal and stem cell origin of blood cell neoplasms. In Contemporary Hematology/Oncology, Vol. 1. J. Lobue, A. S. Gordon, R. Silber, and F. M. Muggia, editors. Plenum Press Publishing Corp., New York. 1-46.

16. Fialkow, P. J. 1982. Cell lineages in hematopoietic neoplasia studied with glucose-6-phosphate dehydrogenase cell markers. J. Cell. Physiol. 1(Suppl.):37-43.

17. Bernheim, A., R. Berger, J. D. Preud'Homme, S. LaBaume, A. Bussel, and R. Bazio-Ciozazu. 1981. Philadelphia chromosome positive blood B lymphocytes in chronic myelocytic leukemia. Leuk. Res. 5:331-339.

18. Fialkow, P. J. 1973. Primordial cell pool size and lineage relationships of five human cell types. Ann. Hum. Genet. 37:39-48.

19. Armitage, P. 1981. Statistical Methods in Medical Research. John Wiley and Sons, New York. 111-112. 